\title{
Impact of parasitism and intersexuality on Mediterranean populations of Paracalanus parvus (Copepoda: Calanoida)
}

\author{
Adrianna Ianora, Maria Grazia Mazzocchi, Bruno Scotto di Carlo \\ Stazione Zoologica di Napoli, Villa Comunale, I-80121 Napoli, Italy
}

\begin{abstract}
The incidence of parasitism and intersexuality in the dominant coastal copepod Paracalanus parvus was studied from 1984 to 1986 at a fixed station in the Gulf of Naples, Italy. Parasitic dinoflagellates belonging to the genera Atelodinium and Blastodinium were the most plentiful forms respectively parasitizing the coelomic cavity and gut of their hosts. Infection by species of Atelodinium, the more common of the 2 parasitic groups, seems to be fatal. Parasitized individuals show striking morphological changes in shape and color as well as behavioral anomalies in swimming mode that reflect their poor physical condition. Infection by Blastodinium species is less devastating and does not seem to cause major structural or behavioural modifications. Both groups of parasites induce sexual castration in their hosts. Individuals infected by Atelodinium were seasonal in occurrence with highest abundances corresponding to a decline in $P$. parvus stocks suggesting a strong inverse relationship in the presence of parasites and their hosts. Infection was greatest for juveniles (up to $30 \%$ ) as opposed to females $(8 \%)$ and completely lacking in males. A strong correlation was also observed between the incidence of intersexes and females parasitized by Atelodinium, $20 \%$ of which showed a modification of the P5 approximating that of juvenile and adult males. Most intersexes did not host internal parasites and only rarely were parasitized by Blastodinium suggesting early infection and later abandonment of the host by parasites of the digestive tract. Data are given on the incidence of intersexes in a number of coastal Mediterranean regions. These are discussed in relation to the possible role of parasitism in regulating seasonal fluctuations in species stocks in coastal communities.
\end{abstract}

\section{INTRODUCTION}

Although parasitism is known to be a potential regulator of freshwater copepod populations (Burn 1980, 1985) few studies are available on the incidence of parasitism in marine planktonic copepods. The most detailed accounts of the internal parasitic dinoflagellates of marine copepods are contained in the monographs by Chatton (1920) and Sewell (1951). These works include mainly information on the systematics and life history of the parasites but contain few quantitative estimates of infection rates in copepods. Brief observations on the presence of internal parasites are also given by With (1915), Steuer (1923), Vane (1952), Marshall \& Orr (1955) and Corkett \& McLaren (1978). A few studies also attempt to describe the potential physiological and morphological effects of parasitism (Jepps 1937, Cattley 1948). More recently, Pasternak et al. (1984) have determined internal photosynthetic rates of the genus Blastodinium parasitizing the offshore copepod Eucalanus subtenuis and hypothesized the potential role of parasitism in supplementing nutritional needs in food-poor environments.

Intersexes have been recorded sporadically among the copepods as early as 1864 by Boeck and by many other authors including With (1915), Früchtl (1924), Vervoort (1946) and Conover (1963), and Sewell (1951) has hypothesized that intersexuality and sexual castration in copepods are probably the direct consequences of juvenile and adult parasitism. Parasitized females have immature gonads and undeveloped genital ducts. In addition, the first 2 segments of the urosome may not fuse to form the genital segment but remain separate as 5 segments, resembling the male condition. Another character change may consist of the development in infected females of an asymmetrical fifth pair of legs, once again resembling the male condition. According to Chatton (1920), parasitism in males arrests develop- 
ment of the last copepodid stage $\mathrm{V}$ with failure to moult to the adult stage. The degree to which these abnormalities are manifested in males and females seems to depend on the developmental stage at which infection occurs with the most profound effects arising from early infection.

Parasitism and intersexuality in marine copepods are generally considered rare events. Chatton (1920) and Sewell (1951) report very low infestation, generally less than $1 \%$, for a number of coastal and offshore species.

Vane (1952), however, gives mean infection rates of $3.7 \%$ with peak values of $60 \%$ for parasitized Calanus finmarchicus sampled in the North Sea. Our own recent investigations of coastal zooplankton indicate that most copepod species are frequently infected by internal parasites. Commonly parasitized copepods in the Gulf of Naples include most species of the genera Clausocalanus, Oithona, Oncaea, Corycaeus, and Scaphocalanus, dominant coastal forms such as Acartia clausi, Centropages typicus, and Ctenocalanus vanus, and many others.

This study is the first attempt to quantify infection rates by internal parasites and the incidence of intersexuality in Paracalanus parvus, one of the most dominant copepods recorded in coastal Mediterranean regions (Scotto di Carlo \& Ianora 1983). We have found this species frequently infected with parasitic dinoflagellates belonging to the genus Blastodinium Chatton 1906 and Atelodinium Chatton 1920 that parasitize, respectively, the gut or coelomic cavity of their hosts. According to Chatton, parasitism probably occurs by ingestion of mobile dinospores or cysts. In Blastodinium, the single cell divides rapidly giving rise to a number of daily generations of 32 to 256 dinospores that are set free into the alimentary canal before final expulsion from the anus.

In the coelomic parasite Atelodinium, the earliest known stage of infection is a small plasmodial mass which is embedded in the connective tissue on the dorsal part of the mid-gut. As it grows the plasmodium develops into a dense mass which progressively invades the haemocoele causing the destruction of internal organs. Sporulation occurs when the parasite has filled the entire body cavity. The spores are then released through the aperture that is opened by a rupture of the antennule, causing the death of the host.

\section{MATERIALS AND METHODS}

Paracalanus parvus specimens were examined for the presence of internal parasites during the course of bi-weekly zooplankton collections from October 1984 to February 1986 at a coastal station in the Gulf of Naples. Numerous specimens were found to be infected with either the coelomic parasite Atelodinium sp. or parasites of the genus Blastodinium that lay within the lumen of the alimentary canal of their hosts. Infected individuals were separated according to type of infection, measured, and examined for external morphological changes. Such individuals were later dissected to identify the parasite and possible internal disorders induced by parasitism. Seasonal oscillations in percentage of infected individuals were calculated for both adult and juvenile $P$. parvus populations. The incidence of parasitism by Atelodinium was easily obtained from samples since infected individuals showed drastic morphological changes in shape and color. By contrast, it was difficult to detect the presence of Blastodinium due to the opacity of preserved specimens. Since this was often possible only after dissection of $P$. parvus, live specimens have been sampled sporadically in coastal waters of the Gulf of Naples since autumn 1985 and the incidence of parasitism by Blastodinium has been tentatively calculated from live populations. Ninety-eight live specimens infected with Atelodinium and 12 with Blastodinium have also been isolated and kept in the laboratory to observe egg deposition and viability as well as behavioural anomalies with respect to healthy individuals.

Randomly selected, healthy and infected Paracalanus parvus females were also examined for the presence of an asymmetrical fifth pair of legs in preserved samples collected from January 1984 to February 1985 and the percentage of abnormal individuals obtained was used as an index of intersexuality. The percentage occurrence of intersexes was recorded monthly except when less than 100 females were counted in the sample. Intersexes were grouped according to type of abnormality of the fifth pair of legs that consisted of the presence of an additional 1, 2 or 3 articles in the left ramus approximating the condition of C IV, C V or adult males, respectively. Body lengths of groups of 100 individuals of the first 2 categories and normal specimens were measured to determine differences in size between intersexes and healthy females. Lengths of abnormal females with a P5 approximating that of adult males were excluded due to the small number of available specimens. All intersexes were dissected to detect the presence of parasites or gross internal and external morphological changes with respect to normal $P$. parvus females.

To verify whether the incidences of parasitism and intersexuality have increased in recent years due to stressful conditions deriving from heavy pollution in the Gulf of Naples environment (Carrada 1983), we examined a number of older collections from the Gulf from 1965 to 1967 . Lastly, regional differences in the incidence of parasitism and intersexes within the Mediterranean were investigated based on zooplank- 
ton collections from the Gulf of Salemo (Tyrrhenian Sea), Gulf of Genoa (Ligurian Sea), Gulfs of Triest and Rijeka (North Adriatic), Lokrum Canal-Dubrovnik and Bay of Ston (South Adriatic), and the Soronikos Gulf (Aegean Sea).

\section{RESULTS}

Female and juvenile Paracalanus parvus infected with coelomic parasites are easily identifiable. They are dark and chubby in appearance due to a pronounced swelling in the prosome with a maximum dilation at the posterior end of the cephalon (Fig. 1). At first glance, they can be easily mistaken for another species of Paracalanus but when probed with a dissecting needle such individuals often release a cloudy mass of dinospores or plasmodial material. On the basis of the morphology of the dinospores, we have tentatively attributed this parasite to the genus Atelodinium Chatton.

Mean values for total body length (TL), prosome length (PL) prosome maximum width (PW), and prosome length-width ratios (PL/PW) are given for healthy

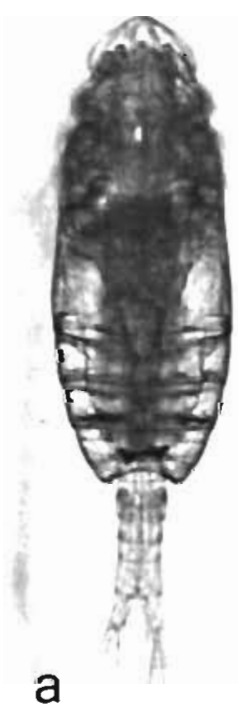

Fig. 1 Paracalanus parvus. (a) Healthy specimen; (b) specimen infected by the parasitic dinoflagellate Atelodinium sp. $(\times 70)$ and infected adult females in Table 1 (prosome sensu Dudley 1986). Infected specimens were larger in size for all variables considered with highly significant differences in TL and PL/PW using a 1-way analysis of variance $\left(\mathrm{p}<10^{-4}\right)$.

The external morphology of infected individuals did not present other gross character changes except that adult females retained the juvenile character of the separation between the 4 th and 5 th somites. We have never observed parasitized adult males although infected juveniles with male characters were often present in our samples.

Internally, the parasite was more densely packed within the prosome region and upon dissection it was seen to fill the entire body cavity of its host causing a reduction in the volume of the stomach and a degeneration of the gonads. No egg deposition has ever been observed for such females.

The most striking behavioural change we have observed in individuals infected with coelomic parasites was in their mode of swimming. Whereas the swimming pattern of healthy Paracalanus parvus females was smooth and punctuated by short bursts of rapid movement, heavily infected individuals were slow and clumsy swimmers and were unable to respond to a probe by characteristic speed-bursts. Their swimming patch traced a series of wide spiral loops emphasizing their poor physical condition.

Paracalanus parvus is the most abundant neritic species in the Gulf of Naples. From January to December 1985, it comprised mean annual values of $18 \%$ of total copepod numbers at our fixed station in the inner part of the Gulf Maximum abundances were observed in the late spring-summer period when values greater than $50 \%$ of total copepod numbers were recorded (Fig. 2A). Individuals infected with Atelodinium were markedly seasonal in their occurrence. Maximum percentage abundances were observed in mid-summer and autumn corresponding to a decline in $P$. parvus stocks. Inversely, infected individuals were completely absent for extended periods of the year immediately preceeding $P$. parvus maximum annual values. Juveniles were more heavily parasitized than adults with values reaching up to $30 \%$ of total juvenile numbers. Maximum infection rates for adult females were about $8 \%$ (Fig. 2B).

Table 1. Paracalanus parvus. Mean body dimensions in $\mathrm{mm} \pm \mathrm{SD}$ for healthy adult females and females parasitized with Atelodinium sp. including total body length (TL), prosome length (PL), prosome width (PW) and prosome length/width ratios (PL/ PW). Means for 100 individuals

\begin{tabular}{|ccccc|}
\hline P. parvus & TL & PL & PW & PL/PW \\
\hline Healthy females & $0.857 \pm 0.052$ & $0.656 \pm 0.039$ & $0.275 \pm 0.020$ & $2.394 \pm 0.134$ \\
Parasitized females & $0.916 \pm 0.044$ & $0.706 \pm 0.034$ & $0.368 \pm 0.025$ & $1.926 \pm 0.110$ \\
\hline
\end{tabular}




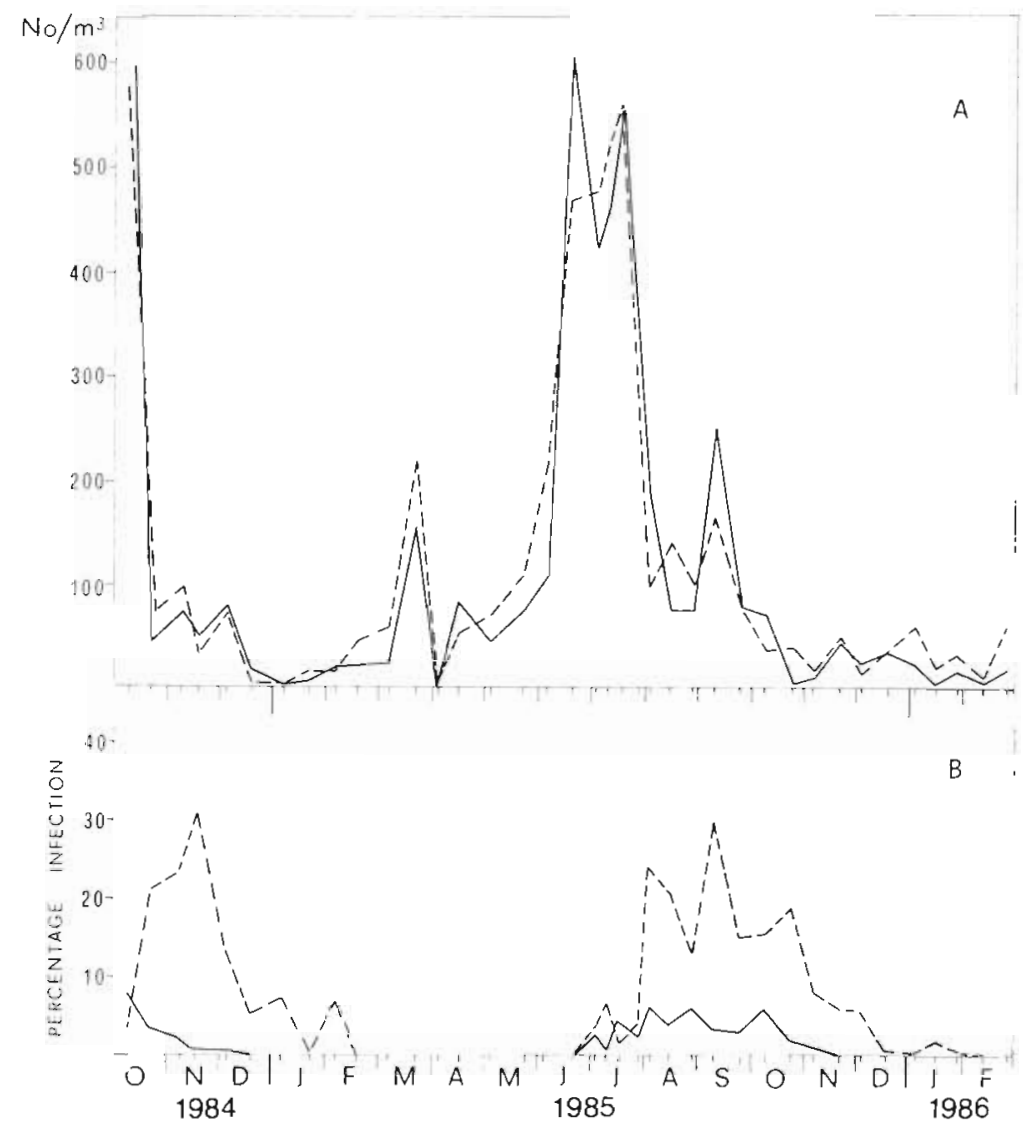

Fig. 2. Paracalanus parvus. Annual fluctuations in adult (continuous line) and juvenile (dashed line) populations sampled from Oct 1984 to Feb 1986 at a fixed station in the Gulf of Naples (A), and corresponding percentage infection rates for adult females (continuous line) and juveniles (dashed line) parasitized by Atelodinium sp. (B)

Parasitic dinoflagellates that lay within the digestive tract of Paracalanus parvus did not induce gross morphological changes in size, color or shape of their hosts. For this reason, it was difficult to detect their presence in preserved material. Such parasites are easily recog-

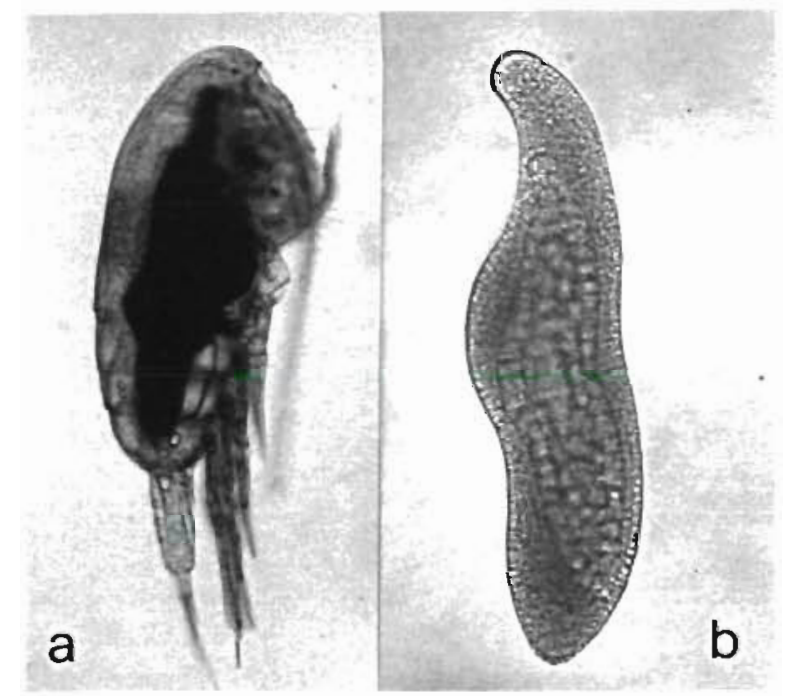

Fig. 3. Paracalanus parvus. (a) Specimen parasitized by Blastodinium sp. $(\times 60)$; (b) triblastic stage of the parasite $B$. contortum $(\times 100)$ nizable in live specimens since they appear as one or more greenish-brown cylindrical lobes that occupy the greater part of the digestive tract (Fig. 3a). Morphologically, the parasite is readily attributable to the genus Blastodinium Chatton. Of the 7 species described by Chatton, we have been able to identify with certainty only $B$. hyalinum and $B$. contortum due to their peculiar shape (Fig. 3b). Of the 2860 specimens examined to date, $12(0.4 \%)$ were parasitized by Blastodinium suggesting that infection rates are markedly lower than those reported for Atelodinium. As in the case of coelomic parasites, infection seems to be greatest for juveniles $(1.2 \%)$ as compared to females $(0.3 \%)$ and completely lacking in males. The few females that we have been able to maintain in the laboratory did not show any apparent morphological or behavioural anomalies. Egg deposition did not occur in any of the females although gonadal material was at times observed in dissected individuals.

Adult Paracalanus parvus females often showed the presence of an aberrant 5th pair of legs. In typical females, the legs are symmetrical and each is composed of a single article whereas in males the P5 is asymmetrical with 4 articles in the left ramus (Fig. 4 a, e). Abnormal females showed a masculinization in the character of the 5 th pair of legs that consisted of the presence of an additional 1, 2 or 3 articles in the left 


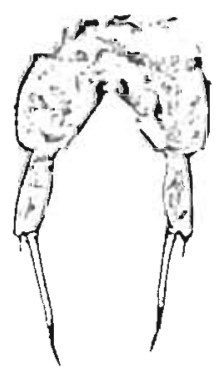

a

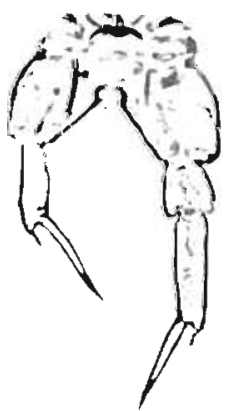

b
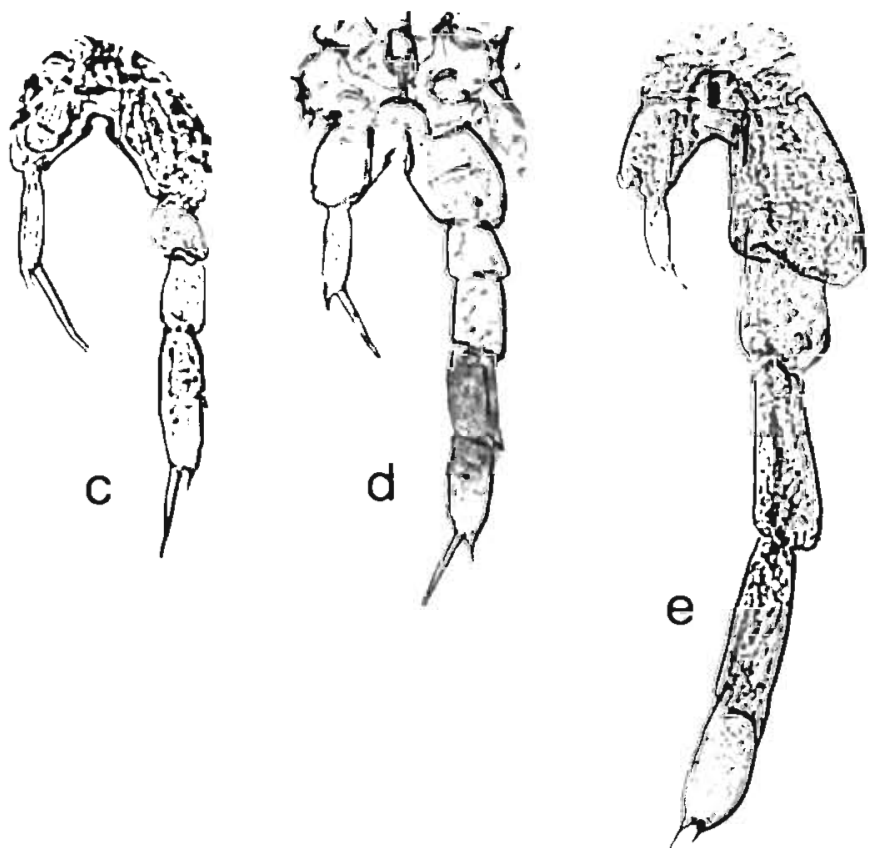

Fig. 4. Paracalanus parvus. Graded series of modifications in P5 of adult females. From left to right: normal adult female (a); females possessing an additional 1 (b), 2 (c) and 3 (d) articles in the left ramus approximating that of normal adult males (e) $(\times 450)$

ramus corresponding to the C IV, C V or adult male condition. The most common occurrences in our samples were of the first and second type (Fig. 4b, c) whereas females with an adult male P5 were very rare (Fig. 4e). All other external morphological characters in such intersexes were typically female including shape, color and the presence of a well-developed genital segment and clearly-defined spermathecae (Fig. 5).

Intersexes were observed in both parasitized females

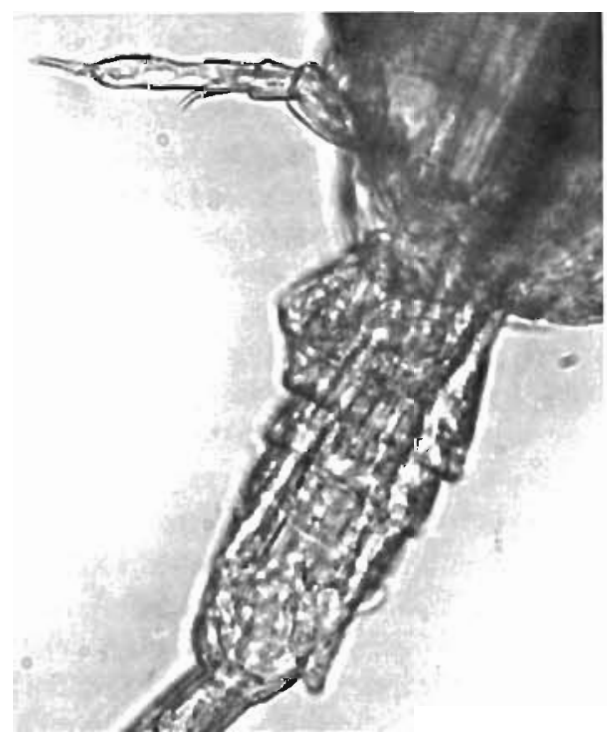

Fig. 5. Paracalanus parvus. Intersex with fully developed female genital segment and modified male-type P5 $(\times 220)$ and presumably healthy individuals lacking internal parasites but the incidence of intersexuality was more frequent in occurrence if the specimen was infected. In the case of females parasitized by Atelodinium, $20 \%$ of the individuals examined had an aberrant P5. Differences were also observed in gonad development. Whereas the gonads were completely destroyed in intersexes infected with Atelodinium, gonadal material with an apparently normal mass of developing oocytes was often observed in intersexes lacking internal parasites or in the few cases when they were infected by Blastodinium. Unfortunately, it was impossible to isolate intersexes from live material since they could only be identified after dissection of the P5. We therefore have no data on egg deposition and viability for such individuals.

Intersexes were observed year-round at our fixed station in the Gulf with percentage values oscillating between $0.7 \%$ and $8.2 \%$ of the total adult Paracalanus parvus female population. In contrast to our observations on parasitized females, no definable seasonal pattern was observed in the occurrence of intersexes (Fig. 6).

To better define the spatial and long-term occurrences of intersexes we have examined a number of older collections from the Gulf of Naples and other coastal Mediterranean regions. The values reported in Table 2 indicate that intersexes frequently occur in coastal Mediterranean areas, at times comprising up to $10 \%$ of the total Paracalanus parvus female population. Although the fragmentary data do not allow for 


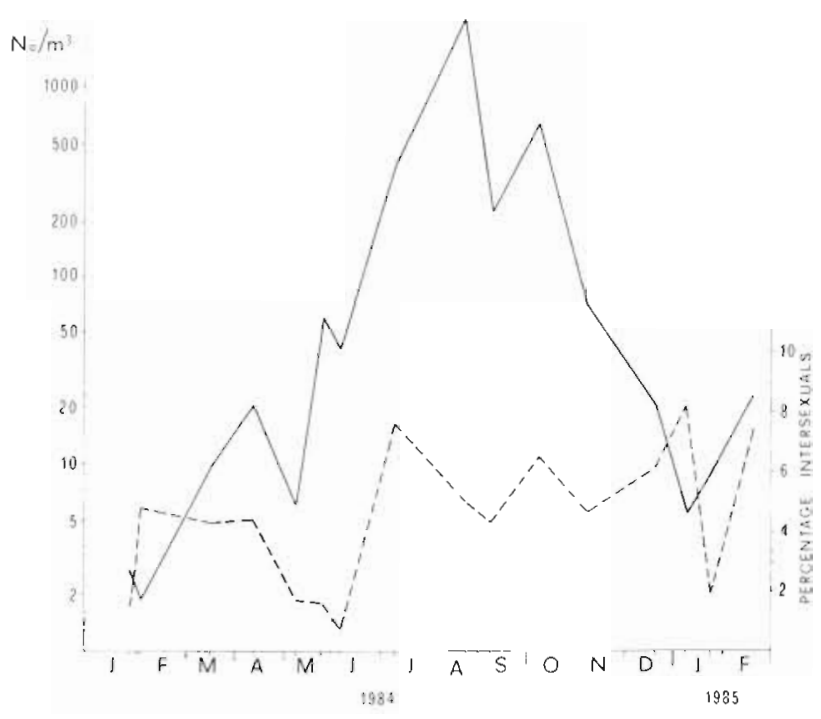

Fig. 6. Paracalansu parvus. Annual fluctuations in adult females and percentage of intersexes observed from Jan 1984 to Feb 1985 at a fixed station in the Gulf of Naples

any statistical analysis they suggest that there are no major interregional differences in the presence of intersexes. Furthermore, on the basis of samples examined along inshore-offshore transects in the Gulf of Salerno, we cannot at present define a gradient in the occurrence of intersexes since these values lie within the range of values reported for our fixed station in the Gulf of Naples. Lastly, samples collected over 20 yr ago confirm the presence of intersexes on earlier sampling dates.

\section{DISCUSSION}

Although early observations on the presence of internal copepod parasites date back to the beginning of the century, there are no recent publications that assess the impact of parasitism on marine copepod communities. In Paracalanus parvus, the main form of infestation includes parasites that induce gross changes in the external and internal morphology of their hosts. Individuals infected with the coelomic parasite Atelodinium are dark and dilated in appearance showing a progressive reduction in the volume of the stomach and a degeneration of the gonads. Such specimens also display changes in swimming mode being more sluggish in their movements than their healthy female counterparts. According to Chatton (1920), this form of infestation is the most devastating and eventually leads to the death of the host. Our results may lend support to this hypothesis since the much higher incidence of parasitism in juveniles denotes that many are unable to reach sexual maturity. Mortality resulting from parasitism would also explain the inverse relation between the seasonal occurrence of parasites and their hosts. We have never observed parasitized adult males. Chatton hypothesized that parasitism arrests the development of male copepods by inhibiting their final moult. The absence of parasitized males could also reflect their lower probability of infection as opposed to females since males are frequently short-lived or have reduced feeding capacities (Marshall \& Orr 1955).

A less devastating form of infestation is that induced by parasites that lie in the digestive tract of their hosts. Paracalanus parvus specimens infected with Blastodinium are perfectly normal in appearance except for a more or less accentuated dilation of the stomach depending on the size and number of parasites present. The less devastating nature of parasitic infection by Blastodinium may be confirmed on the basis of recent observations by Pasternak et al. (1984). These authors define Blastodinium as a semi-parasitic alga that obtains only part of its nourishment from its host, the remainder being derived from photosynthetic activity that may contribute up to $50 \%$ of the nutritional requirements of the parasite.

Though infection by Blastodinium may not be fatal, it

Table 2. Paracalanus parvus. Regional differences in the minimum, maximum and mean percentage occurrences of intersexes in coastal and offshore (') Mediterranean areas

\begin{tabular}{|c|c|c|c|c|c|c|}
\hline Locality & & Period & No. stns examined & No. ind. examined & Min-max. \% & Mean \% \\
\hline \multirow{2}{*}{\multicolumn{2}{|c|}{ Naples }} & $1965-1967$ & 5 & 2197 & $4.6-7.8$ & 6.28 \\
\hline & & Jun-Aug '73 & 17 & 1583 & $1.4-9.7$ & 3.16 \\
\hline Salerno ${ }^{\circ}$ & & Nov 81 , Jul 82 & 12 & 1504 & $0-4.2$ & 1.26 \\
\hline Salerno & & Nov' 81 & 2 & 320 & $1.7,4.0$ & 3.13 \\
\hline \multirow[t]{4}{*}{ Adriatic: } & Triest & Apr ' 84 & 1 & 1390 & 0.9 & 0.90 \\
\hline & Rijeka & Feb 73 & 2 & 724 & $0.5,2.6$ & 2.07 \\
\hline & Ston & Mar, Jun 80 & 2 & 1289 & $0.5,1.0$ & 0.78 \\
\hline & Lokrum & Mar, May 77 & 2 & 806 & $1.6,4.0$ & 2.11 \\
\hline Genoa & & Apr-Nov 79 & 6 & 1268 & $0-1.6$ & 1.03 \\
\hline Soronikos & & Jan, Nov' 86 & 2 & 430 & $1.0,4,8$ & 3.02 \\
\hline
\end{tabular}


may produce equally harmful effects on host reproduction as does Atelodinium. Large Blastodinium species as shown in Fig. 3 seem to induce sexual castration in their hosts by compressing the space occupied by the gonads thereby impeding their normal development. It is not evident, however, how smaller forms affect reproduction since gonadal material is often observed in infected females. It is probable, as Jepps (1937) suggests, that the ovaries of parasitized females contain irregular oocytes with degenerate nuclei.

It has often been postulated that parasitism induces intersexuality in copepods. In Paracalanus parvus, however, most of the intersexes were not parasitized implying that intersexuality may either appear during the life history of an individual without the accompanying presence of internal parasites or result from early infection from which the individual has later recovered (Sewell 1951). If intersexuality is an indirect expression of parasitism, the presence of a male-type P5 in adult females is attributable to masculinization in secondary sexual characters in developing females (Sewell 1951) or to sex reversal prior to the last moult in males that become superficially mature but sterile females (Cattley 1948). In $P$. parvus infected with Atelodinium, a $20 \%$ incidence of adult females with a modified P5 indicates a strong correlation between parasitism and the occurrence of intersexes, when compared to a maximum of about $8 \%$ in the case of normal females. By contrast, a modification in the P5 in individuals that only rarely hosted internal parasites of the genus Blastodinium suggests early infection by parasites that are later capable of abandoning their hosts as has been observed at times while handling live $P$. parvus specimens. At the present state of our knowledge, however, we lack information as to whether such intersexes are capable of recovering from early infection or if they represent a permanently sterile fraction of the population.

Though often neglected, parasitism may play an important role in controlling seasonal abundance cycles in coastal copepod populations. At the individual level, parasitism can arrest development, induce intersexuality, cause sterility and even death in the host (Chatton 1920). The resulting injurious effects at the community level will depend on the frequency of occurrence of parasitism in natural populations.

Our results for the Gulf of Naples attest the high incidence of parasitism in one of the most dominant copepods present in coastal Mediterranean areas with infection rates as high as $30 \%$ for juveniles and $8 \%$ for adult Paracalanus parvus females parasitized by Atelodinium. Furthermore, our present and past data on inter-regional differences in the occurrence of intersexes shed light on the relative importance of parasitism in other Mediterranean regions. However, these results do not give evidence that infection is more frequent in areas subjected to heavy pollution such as the Gulfs of Naples, Rijeka (Jeftic et al. 1980) and Soronikos (Moraitou-Apostolopoulou \& Ignatiades 1980), or that infection prevails in coastal populations of $P$. parvus. At this point, further studies are warranted to better define the complex host-parasite relationship and the potential role of parasitism in structuring marine copepod communities.

Acknowledgements. We thank C. Gargiulo for his photographic work and Drs George D. Grice and Carmelo Tomas for their helpful criticism of the manuscript. Thanks are also due to Drs A. Carli, J. Hure, S. Fonda Umani and O. Armeni for having sent us zooplankton samples from various Mediterranean regions.

\section{LITERATURE CITED}

Boek, A. (1864). Oversigt over de ved Norgeskyster iagttague Copepoder henhorende til Calanidernes, Cyclopidernes, og Harpactidernes Familier. Chr. Vid. Selsk. Forh. 7: 226-282

Burns, C. W (1980). Occurrence of Aphanomyces ovidestruens, a fungus parasitic on copepods, in two eutrophic lakes. N. Z. Jl mar Freshwater Res. 14: 23-29

Burns, C. W. (1985). Fungal parasitism in a copepod population: the effects of Aphanomyces on the population dynamics of Boeckella dilatata Sars. J. Plankton Res. 7 : 201-205

Carrada, G. C. (1983). The Gulf of Naples and its data base. In: Carrada, G. C., Hopkins, T S., Jeftic, Lj, Morcos, S. (ed.) Quantitative analysis and simulation of Mediterranean coastal ecosystems: the Gulf of Naples, a case study. Unesco Rep. Mar. Sci. 20: 70-79

Cattley, J. C. (1948). Sex reversal in copepods. Nature, Lond. 161: 937

Chatton, E. (1920). Les péridiniens parasites. Morphologie, reproduction, éthologie. Archs Zool. exp. gén. 59: 1-475

Conover, R. J. (1963). An intersex in Calanus hyperboreus. Crustaceana 8: 153-158

Corkett, C. J., McLaren, I. A. (1978). The biology of Pseudocalanus. Adv. mar Biol. 15: 1-231

Dudley, P. L. (1986). Aspects of general body shape and development in Copepoda. Syllogenus 58: 7-25

Früchtl, F. (1924). Die Cladoceren und Copepoden-Fauna des Aru-Archipels. Arb. aus d. Zoolog. Institut d. Universität Innsbruck 2: 1-114

Jeftic, L., Kuzmic, M., Orlic, M., Policastro, A. J. (1980). Investigations of Rijeka Bay in the framework of MEDPOL VI. V Journées Etud. Pollution, CIESM: 901-910

Jepps, M. W. (1937). On the protozoan parasites of Calanus finmarchicus in the Clyde Sea area. Q. J. microsc. Sci. 79: $589-658$

Marshall, S. M., Orr, A. P. (1955). The biology of a marine copepod Calanus finmarchicus (Gunnerus). Oliver and Boyd, Edinburgh

Moraitou-Apostolopoulou, M., Ignatiades, L. (1980). Pollution effects on the phytoplankton-zooplankton relationships in an inshore environment. Hydrobiologia 75: 259-266

Pasternak, A. F., Arashkevich, YE. G., Sorokin, YU. S. (1984). The role of the parasitic algal genus Blastodinium in the ecology of planktonic copepods. Oceanology 24: 748-751 
Scotto di Carlo, B., Ianora, A. (1983). Standing stocks and species composition of Mediterranean rooplankton. In Carrada, G. C., Hopkins, T S., Jeftic, Lj., Morcos, S. (ed.) Quantitative analysis and simulation of Mediterranean coastal ecosystems: the Gulf of Naples, a case study. Unesco Rep. Mar. Sci. 20: 59-69

Sewell, R. B. S. (1951). The epibionts and parasites of the planktonic Copepoda of the Arabian Sea. John Murray Expedition. Sci. Rep. B. M. (N. H.) 9: $25 j 394$

Steur, A. (1923). Copepoda 6: Pleuromamma Giesbr. 1898 der
Deutschen Tiefsee Expedition. Wiss. Ergebn. dt. Tiefsee Exped. 24: 1-117

Vane, F. R. (1952). The distribution of Blastodinium hyalinum in the North Sea. Challenger Soc. 3: 23-24 (1952)

Vervoort, W. (1946). The bathypelagic Copepoda Calanoida of the Snellius Expedition I. Families Calanidae, Eucalanidae, Paracalanidae and Pseudocalanidae. Biological Results of the Snellius Expedition XV Temminckia 8: 1-181

With, C. (1915) Copepoda I. Calanoida Amphascandria Dan Ingolf-Exped. 3: 1-260

Editorial responsibility: Managing Editor; accepted for printing on July 1, 1987 